\title{
CATALYTIC PERFORMANCE OF COPPER-MANGANESE SUPPORTED ON ACTIVATED CARBON SYNTHESIZED BY DEPOSITION-PRECIPITATION METHOD
}

\author{
Melody Kimi ${ }^{1}{ }^{凶}$, Bibie Nur Syafiqah Safiuddin², Suh Cem Pang ${ }^{2}$
}

https://doi.org/10.23939/chcht14.01.032

\begin{abstract}
CuMn}_{x} /$ activated carbon (AC, $x=0.1,0.2,0.5$ and 1) nanoparticles were prepared by depositionprecipitation method. The catalytic performance of $\mathrm{CuMn}_{x} / \mathrm{AC}$ catalysts were studied for the oxidation of benzyl alcohol to benzaldehyde. The molar ratio of $\mathrm{Mn}$ plays an important role in the catalytic performances. The optimum amount of $\mathrm{Mn}$ is 0.1 with the highest benzyl alcohol conversion of $63 \%$.
\end{abstract}

Keywords: benzyl alcohol oxidation, bimetallic catalyst, activated carbon, copper, manganese.

\section{Introduction}

Selective catalytic oxidation of alcohols to produce the corresponding aldehydes and ketones, in particular, benzyl alcohol to benzaldehyde has been regarded as one of the most important organic transformations in industrial chemistry $[1,2]$. Benzaldehyde has been widely applied in the manufacture of odorants, flavours and pharmaceutical intermediates as an important raw material [3]. It is generally prepared in the industry either by hydrolysis of benzyl chloride or by oxidation of toluene [4]. Environmental concern has forced researchers to explore benign synthetic methods. Therefore, many new processes for benzaldehyde synthesis have emerged and catalytic oxidation of benzyl alcohol to benzaldehyde has attracted much attention both in laboratory and chemical industry. The usage of heterogeneous catalyst for the liquid-phase selective oxidation of benzyl alcohol under mild conditions has attracted attention from the viewpoint of sustainable chemical processes $[5,6]$.

Solid catalysts used for the catalytic oxidation of benzyl alcohol to benzaldehyde include metals [7, 8],

\footnotetext{
${ }^{1}$ Centre for Pre-University Studies, University Malaysia Sarawak, Kota Samarahan, Malaysia

2 Department of Chemistry, Faculty of Resource Science and Technology,

University Malaysia Sarawak, Kota Samarahan, Malaysia

«melody@unimas.my

(c) Kimi M., Safiuddin B., Pang S., 2020
}

metal oxides [9] and supported metals or metal oxides [10, 11]. The use of transition metals such as $\mathrm{Cu}[12,13]$ and Mn [9, 14, 15] containing catalysts offer a good alternative in comparison to the expensive noble metals. Choudhary et al. [12] have tested the performance of $\mathrm{Cu}$ containing hydrotalcite-like solid catalysts with $41 \%$ conversion for the oxidation of benzyl alcohol [12]. Encapsulated $\mathrm{Cu}(\mathrm{II})$ complexes in zeolite-Y also showed a conversion of $29 \%$ for similar reaction [16]. Manganese oxide is extensively studied because of its strong oxygen storage/release ability, excellent redox properties and low cost $[17,18]$. Manganese oxide was reported as a superior catalyst for the aerobic oxidation of benzyl alcohol in liquid-phase with up to $100 \%$ selectivity [19]. The catalytic activity of Mn species was very much dependent on the oxidation state [20].

Supported metal catalyst has been proven to improve the selective conversion of benzyl alcohol to benzaldehyde by oxidation reaction. The use of activated carbon (AC) as a catalyst support to immobilised metal catalyst offers advantages such as high surface area and corrosion resistance [21]. Both the texture and surface chemistry of AC support have distinct effect on the catalytic performance of AC supported catalysts [22, 23]. The ability of AC to activate molecular oxygen that is essential for oxidation reaction was also reported [24].

A comparative catalytic study was carried out to evaluate the catalytic performance of $\mathrm{CuMn}_{x} / \mathrm{AC}$ for the selective oxidation of benzyl alcohol. The catalytic performance in the liquid-phase oxidation of benzyl alcohol with hydrogen peroxide as the oxidant was examined and the influence of $\mathrm{Mn}$ mol ratio has been thoroughly investigated. The $\mathrm{CuMn}_{0.1} / \mathrm{AC}$ showed the best catalytic performance, which suggests that the amount of Mn play a crucial role. Typically, a high conversion of $63 \%$ as well as product selectivity of $>99 \%$ was achieved within very short reaction time $(2 \mathrm{~h})$ under mild conditions. The characterization results showed the particle size and metal dispersion are dependent on the Mn loading which are then interrelated with the catalytic performances. 


\section{Experimental}

\subsection{Catalysts Preparation}

The $\mathrm{CuMn}_{x} / \mathrm{AC}(x=0.1,0.2,0.5,1)$ nanoparticles catalyst were prepared by using homogeneous depositionprecipitation method previously reported with slight modification $[25,26]$. In brief, for the synthesis of $\mathrm{CuMn}_{0.1} / \mathrm{AC}$ catalyst, $1.0 \mathrm{~g}$ of $\mathrm{AC}$ was added to $50 \mathrm{ml}$ aqueous solution of $0.1 \mathrm{~mol}$ of $\mathrm{Cu}\left(\mathrm{NO}_{3}\right)_{2} \cdot 3 \mathrm{H}_{2} \mathrm{O}$ and $0.01 \mathrm{~mol}$ of $\mathrm{Mn}\left(\mathrm{NO}_{3}\right)_{2} \cdot 4 \mathrm{H}_{2} \mathrm{O}$ under stirring at room temperature. The resulting mixture was stirred for $15 \mathrm{~min}$ and $0.1 \mathrm{~mol} \cdot \mathrm{l}^{-1}$ of $\mathrm{NaOH}$ was added dropwise, under vigorous stirring at room temperature until the $\mathrm{pH}$ became 10.0. The resulting solution was kept at room temperature for $24 \mathrm{~h}$, centrifuged and washed with deionized water until neutral $\mathrm{pH}$. The prepared sample was dried at $383 \mathrm{~K}$ overnight followed by calcination at $823 \mathrm{~K}$ in air for $3 \mathrm{~h}$. To compare the catalytic activities, single metal catalyst $\mathrm{Cu} / \mathrm{AC}$ and $\mathrm{Mn} / \mathrm{AC}$ catalysts were also prepared using the same method.

\subsection{Catalysts Characterisation}

X-ray diffraction (XRD) patterns of the catalysts were obtained by D8 Advance (BRUKER AXS, Germany) diffractometer using $\mathrm{Cu} \mathrm{K} \alpha$ radiation $(\lambda=1.541 \AA)$ from $20^{\circ}$ to $70^{\circ}$ to investigate the structural properties. Scanning Electron Microscope (SEM) images were taken using JSM-6390 (JEOL, USA) to identify the morphology and estimate the particle size of the catalysts. Transmission electron microscopy (TEM) photographs were taken with a JEOL JEM-2999FMII apparatus. Samples for TEM were prepared by placing a drop of a colloidal dispersion of catalyst in an ethanol solvent onto a perforated copper grid, followed by naturally evaporating the solvent. The mean particle diameters were calculated by nano measurer software from TEM image analysis.

\subsection{Evaluation of Catalytic Performance}

Liquid phase oxidation of benzyl alcohol was carried out using procedures that were reported previously with slight modification [27]. In a typical reaction, $2.6 \mathrm{ml}$ (25 mmol) of benzyl alcohol, $3.3 \mathrm{ml}(32 \mathrm{mmol})$ of $30 \%$ $\mathrm{H}_{2} \mathrm{O}_{2}$ and $0.1 \mathrm{~g}$ of the catalyst powder were loaded in a $50 \mathrm{ml}$ double neck round bottom flask containing $20 \mathrm{ml}$ of toluene as solvent. The flask was connected to a reflux condenser, magnetically stirred and kept in an oil bath at $353 \mathrm{~K}$ for $2 \mathrm{~h}$. After reaction, the solid catalysts were separated by centrifugation and the liquid samples were filtered and analysed by gas chromatography to evaluate the products by GC-MS (SHIDMADZU QP 5000) equipped with a flame ionization detector (FID) and a medium polarity capillary column (BPX-5 column $(29.4 \mathrm{~m} \times 0.25 \mathrm{~mm})$, with film thickness of $0.25 \mu \mathrm{m}$ and with helium as the carrier gas.

\section{Results and Discussion}

\subsection{Crystal structure of catalysts}

X-ray diffraction was employed to analyse the effect of $\mathrm{Mn}$ addition into $\mathrm{Cu} / \mathrm{AC}$ and the amount of $\mathrm{Mn}$ on the crystalline structure and phase of the samples. XRD patterns of the single metal $\mathrm{Cu} / \mathrm{AC}, \mathrm{Mn} / \mathrm{AC}$ and $\mathrm{CuMn}_{x} / \mathrm{AC}(x=0.1,0.2,0.5$ and 1$)$ samples were shown in Fig. 1. The weak diffraction peak at $2 \theta=26.5^{\circ}$ observed for all the samples was assigned to the activated carbon support [28] with hexagonal phase according to PDF no. 01-071-3739. For $\mathrm{Cu} / \mathrm{AC}$ sample, three major peaks could be observed at $2 \theta=35.5^{\circ}, 38.7^{\circ}$ and $48.7^{\circ}$ which were attributed to (111) and (202) planes, respectively, for $\mathrm{CuO}$ hexagonal phase. The peaks are in good agreement with PDF no. 00-045-0937. There were also impurity peaks observed at $2 \theta=36.4^{\circ}$ and $42.3^{\circ}$ that correspond to (111) and (200) of $\mathrm{Cu}_{2} \mathrm{O}$. As for $\mathrm{Mn} / \mathrm{AC}$ sample, two major diffraction peaks at $2 \theta=32.3^{\circ}$ and $36.0^{\circ}$ correspond to (103) and (211) planes of $\mathrm{Mn}_{3} \mathrm{O}_{4}$ tetragonal phase with PDF no. 01-089-4837.

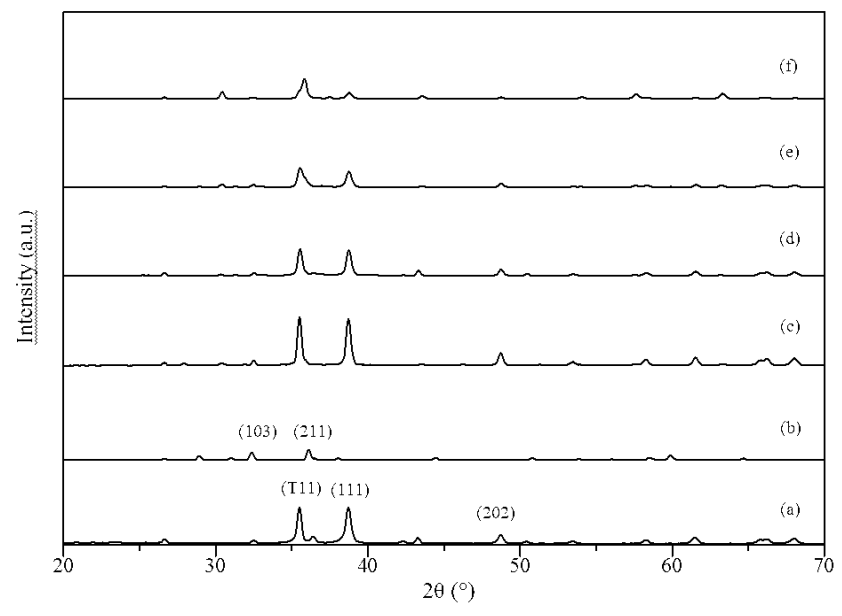

Fig. 1. Powder XRD pattern of $\mathrm{Cu} / \mathrm{AC}(\mathrm{a}), \mathrm{Mn} / \mathrm{AC}(\mathrm{b})$, $\mathrm{CuMn}_{0.1} / \mathrm{AC}$ (c), $\mathrm{CuMn}_{0.2} / \mathrm{AC}$ (d), $\mathrm{CuMn}_{0.5} / \mathrm{AC}$ (e) and $\mathrm{CuMn}_{1} / \mathrm{AC}$ catalyst (f)

All $\mathrm{CuMn}_{x} / \mathrm{AC}$ samples had peaks that correspond to hexagonal $\mathrm{CuO}$. Due to the weak crystalline peaks of $\mathrm{Mn}_{3} \mathrm{O}_{4}$, it was not observed in $\mathrm{CuMn}_{x} / \mathrm{AC}$ samples, although the characteristic peaks for $\mathrm{Cu}$ and $\mathrm{Mn}$ were quite close to distinguish. This also indicates high dispersion of Mn particles over the catalyst surface [29]. An influence in 
peak intensity of coexisting phase between $\mathrm{CuO}$ and $\mathrm{Mn}_{3} \mathrm{O}_{4}$ can be detected. Peaks corresponding to $\mathrm{Cu}_{2} \mathrm{O}$ also disappeared with the addition of $\mathrm{Mn}$. $\mathrm{CuMn}_{0.1} / \mathrm{AC}$ peak intensity increased compared to $\mathrm{Cu} / \mathrm{AC}$, indicating the improvement in the crystallinity. As the amount of $\mathrm{Mn}$ increased, $\mathrm{CuMn}_{x} / \mathrm{AC}$ catalysts exhibited broader characteristic peaks than those of $\mathrm{Cu} / \mathrm{AC}$. This showed that the addition of $\mathrm{Mn}$ affected the crystallinity of the samples. The changes in the crystalline peaks implied that $\mathrm{CuMn}_{x} / \mathrm{AC}$ catalyst was formed. It can be deduced that $\mathrm{Mn}$ had entered the lattice of $\mathrm{CuO}$ [30]. There were no changes in crystal phase of $\mathrm{CuO}$ with the addition of $\mathrm{Mn}$ into $\mathrm{Cu} / \mathrm{AC}$ catalyst. This result evidences that the crystal phase of $\mathrm{CuO}$ is not influenced by the addition of $\mathrm{Mn}$. The addition of $\mathrm{Mn}$ at irrespective amount also did not lead to distortion of the $\mathrm{CuO}$ phase.

With increasing $\mathrm{Mn}$ content, the peaks corresponding to $\mathrm{CuO}$ slightly shifted to higher angle. The peaks shift indicates that $\mathrm{Mn}^{2+}(0.80 \AA)$ with the larger ionic radius have entered into the $\mathrm{CuO}$ lattice to replace $\mathrm{Cu}^{2+}(0.72 \AA)$ ions of smaller ionic radius. The peak shift and crystal shrinking indicated that $\mathrm{Mn}$ may alloy with $\mathrm{Cu}$ to change the crystal lattice of $\mathrm{Cu}$. Similar observation was reported when $\mathrm{Bi}$ was added into $\mathrm{Pt} / \mathrm{CNT}$ [31], which resulted in good contact and synergic effect with each other.

The crystallite size of the catalysts calculated using Scherrer's equation from the broadening of the peak corresponding to the (111) plane and $d$-spacing are tabulated in the Table. The crystallite size of $\mathrm{CuO}$ was found to be smaller compared to $\mathrm{Mn}_{3} \mathrm{O}_{4}$ due to the smaller ionic radius of $\mathrm{Cu}^{2+}$. As for $\mathrm{CuMn}_{x} / \mathrm{AC}$ catalysts, the crystallite size range is around $26-35 \mathrm{~nm}$, which is between the size for both single metal catalysts. There was not much difference in the crystallite sizes when the amount of Mn increased. The slight decrease in crystallite size could be due to defects caused by the addition of Mn. The $d$-spacing of the catalysts also did not differ much as the amount of $\mathrm{Mn}$ increased.

\subsection{Morphology of catalysts}

The morphology and structure of the catalysts were analysed using scanning electron microscope (SEM). Fig. $2 \mathrm{a}$ shows $\mathrm{Cu} / \mathrm{AC}$ samples, which have an estimated diameter of $0.40-1.00 \mu \mathrm{m}$. The AC surfaces are filled with many small and spherical dots of $\mathrm{Cu}$. This showed that $\mathrm{Cu}$ is widely distributed on the surface of $\mathrm{AC} . \mathrm{Mn} / \mathrm{AC}$ (Fig. $2 b)$ showes aggregated particles with irregular shape on $\mathrm{AC}$ surface in the size range of $0.30-1.00 \mu \mathrm{m}$. The addition of $\mathrm{Mn}$ on $\mathrm{Cu} / \mathrm{AC}$ catalyst (Figs. 2c-2f), showed small sphere particles that are well defined in the range of $0.40-0.50 \mu \mathrm{m}$. There were no considerable changes in the particle shape and sizes when the amount of $\mathrm{Mn}$ added increased. However, the addition of $\mathrm{Mn}$ changes the morphology of the catalyst which differs from both $\mathrm{CuO}$ and $\mathrm{Mn}_{3} \mathrm{O}_{4}$. Thus, the presence of $\mathrm{Mn}$ formed a synergistic interaction with $\mathrm{Cu} / \mathrm{AC}$. The slight decrease of the particles size of $\mathrm{Cu} / \mathrm{AC}$ catalyst when $\mathrm{Mn}$ was added could be attributed to the interactions between two metals, known as stabilizing effect [32] as confirmed by XRD. The dispersion of the particles was more uniform as compared to monometallic $\mathrm{Cu} / \mathrm{AC}$ catalyst. Figs. $2 \mathrm{c}-2 \mathrm{f}$ also show that $\mathrm{CuMn}_{x}$ particles have large contact area with $\mathrm{AC}$ support.

The TEM images of $\mathrm{CuMn}_{0.1} / \mathrm{AC}$ catalysts shown in Fig. 3 indicate that the $\mathrm{Cu}$ and $\mathrm{Mn}$ species are distributed uniformly over the surface of AC. It shows that depositionprecipitation method for the synthesis of catalyst prevents the agglomeration of nanoparticles. The particles size of $\mathrm{Cu}$ and $\mathrm{Mn}$ species calculated by nano measure is in the range of $0.2-0.4 \mu \mathrm{m}$, which is similar with SEM. It is worth noting that particle size calculated by TEM is larger than the values calculated by the Scherrer equation. Imaging techniques such as TEM and SEM give the size of the particle, while XRD disclose the size of the crystallite [33].

\subsection{Catalytic Performances}

The performance of single metal $\mathrm{Cu} / \mathrm{AC}, \mathrm{Mn} / \mathrm{AC}$ and various $\mathrm{CuMn}_{x} / \mathrm{AC}(x=0.1,0.2,0.5$ and 1$)$ on the oxidation of benzyl alcohol at $353 \mathrm{~K}$ for $2 \mathrm{~h}$ with $\mathrm{H}_{2} \mathrm{O}_{2}$ as oxidant are summarized in the Table. Pure AC did not show considerable activity for alcohol oxidation. All supported metal catalysts showed catalytic activity with $100 \%$ selectivity to produce benzaldehyde under the conditions applied. It was deduced that the surface of AC was used for oxygen activation and regeneration [34] while metal oxides have strong ability towards alcohol dehydrogenation [24].

Properties and catalytic activity of the catalyst

\begin{tabular}{|c|c|c|c|c|}
\hline Entry & Catalyst & $d$-Spacing, $\mathrm{nm}$ & Crystallite size, $\mathrm{nm}$ & Conversion, $\%$ \\
\hline 1 & $\mathrm{Cu} / \mathrm{AC}$ & 2.3241 & 29.4 & 49.9 \\
\hline 2 & $\mathrm{Mn} / \mathrm{AC}$ & 2.3632 & 41.6 & 32.8 \\
\hline 3 & $\mathrm{CuMn}$ & \\
\hline 4 & $\mathrm{CuMn}_{0.2} / \mathrm{AC}$ & 2.3243 & 35.7 & 63.0 \\
\hline 5 & $\mathrm{CuMn}_{0.5} / \mathrm{AC}$ & 2.3226 & 32.8 & 58.2 \\
\hline 6 & $\mathrm{CuMn}_{1} / \mathrm{AC}$ & 2.3226 & 26.0 & 54.9 \\
\hline
\end{tabular}

Reaction conditions: $0.1 \mathrm{~g}$ catalyst, $2.6 \mathrm{ml}$ benzyl alcohol, $3.3 \mathrm{ml} \mathrm{H}_{2} \mathrm{O}_{2}, 20 \mathrm{ml}$ toluene as a solvent, $T=353 \mathrm{~K}, t=2 \mathrm{~h}$. 

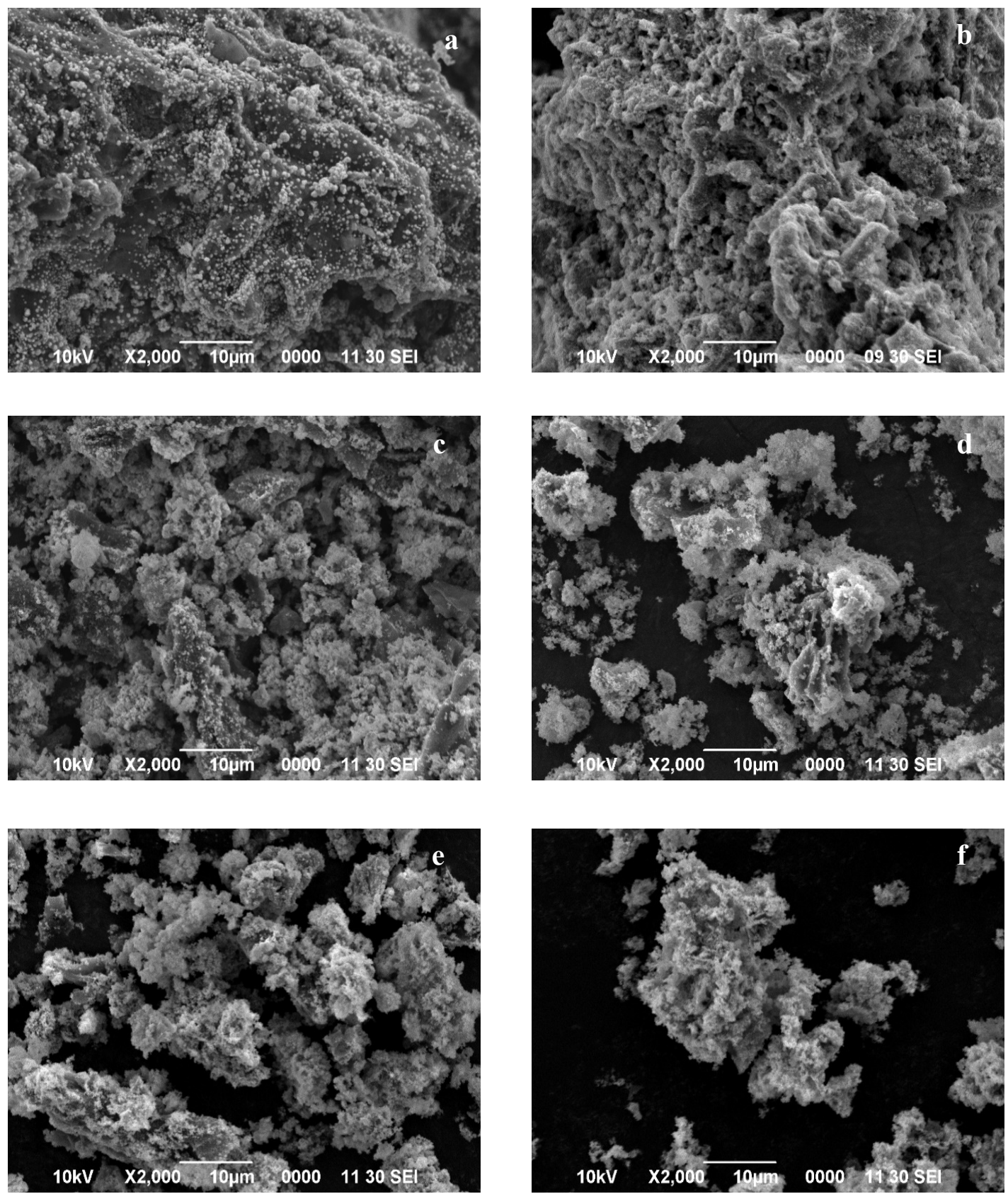

Fig. 2. SEM images of Cu/AC (a), $\mathrm{Mn} / \mathrm{AC}$ (b), $\mathrm{CuMn}_{0.1} / \mathrm{AC}$ (c), $\mathrm{CuMn}_{0.2} / \mathrm{AC}$ (d), $\mathrm{CuMn}_{0.5} / \mathrm{AC}$ (e) and $\mathrm{CuMn}_{1} / \mathrm{AC}$ (f) catalyst

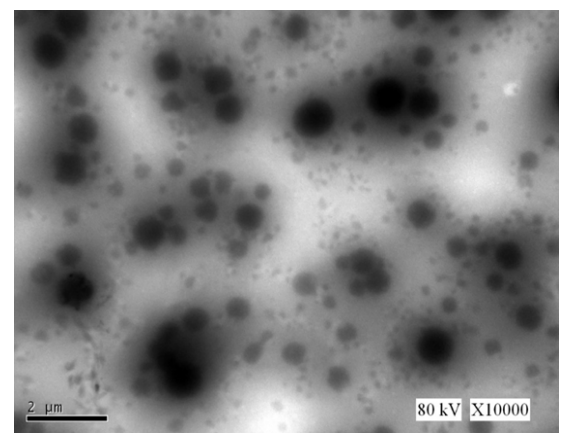

Fig. 3. TEM images of $\mathrm{CuMn}_{0.1} / \mathrm{AC}$ 
From XRD analysis, it can be assumed that the $\mathrm{CuO}$ and $\mathrm{Mn}_{3} \mathrm{O}_{4}$ is highly dispersed on the $\mathrm{AC}$ as the support. This produced synergistic effect when combined. For monometallic $\mathrm{Cu} / \mathrm{AC}$, the conversion of benzyl alcohol was $49.9 \%$. Single metal $\mathrm{Mn} / \mathrm{AC}$ also showed low conversion of benzyl alcohol. Upon the addition of $\mathrm{Mn}$ into $\mathrm{Cu} / \mathrm{AC}$, the catalytic activity improved greatly. Different Mn content resulted in differences in the catalytic performances. The best result was obtained with $\mathrm{CuMn}_{0.1} / \mathrm{AC}$ catalyst, which gave $63.0 \%$ conversion of benzyl alcohol. This effect can be explained by the better crystallinity of this catalyst compared to the others. High crystallinity could be deduced to provide large number of active sites due to higher metal dispersion. The other bimetallic catalyst had slightly higher conversion of benzyl alcohol compared to their monometallic catalyst. However, with further raising the concentration of $\mathrm{Mn}$ until $\mathrm{Cu} / \mathrm{Mn}=1 / 1$, the catalytic activity gradually decreases. The activity of $\mathrm{CuMn}_{1} / \mathrm{AC}$ was even lower than the activity of monometallic $\mathrm{Cu} / \mathrm{AC}$. It was reported that in a bimetallic system of $\mathrm{Cu}$ and $\mathrm{Au}, \mathrm{Cu}$ played significant role in activating oxygen and evidence of electron transfer from $\mathrm{Cu}$ was observed [35]. The synergistic effect originates mainly from the electronic effect in which $\mathrm{Cu}$ and $\mathrm{Mn}$ transfer electron and assists to activate oxygen. The highly dispersed manganese species, coexistence of $\mathrm{Mn}^{2+}$ and $\mathrm{Mn}^{3+}$, were postulated to be the active sites [36] in addition to $\mathrm{Cu}^{2+}$. However, when too much $\mathrm{Mn}$ was added, agglomeration of particles could deter the smooth transfer of electrons [20]. Hence, the particle size and distribution of the active metal species can be tuned by changing the mol ratio of $\mathrm{Mn}$ added. The deposition-precipitation techniques had been shown to afford high dispersion and narrow distribution of metal nanoparticles size [37]. High dispersion of metal active sites provides high accessibility of the reactants [9] to the catalyst, which resulted in high catalytic performances in optimum amount.

\section{Conclusions}

A series of $\mathrm{Cu}-\mathrm{Mn}_{x} / \mathrm{AC}$ catalysts was successfully prepared with deposition-precipitation method. Their catalytic performances were evaluated in the oxidation of benzyl alcohol using hydrogen peroxide as oxidant. Highly dispersed $\mathrm{Cu}$ and $\mathrm{Mn}$ particles were attached to the surface of $\mathrm{AC}$ when the molar ratio of $\mathrm{Mn}$ is 0.1 . $\mathrm{CuMn}_{0.1} / \mathrm{AC}$ possesses the best catalytic activity with $63 \%$ conversion after $2 \mathrm{~h}$. The addition of small amount of $\mathrm{Mn}$ had contributed to the high crystallinity of the catalyst which would enhance the catalytic activity by suppressing the agglomeration of Mn. When Mn loading was above the optimum amount, it decreased Mn dispersion. This will reduce the active metal surface.

\section{Acknowledgements}

This work was supported by University Malaysia Sarawak under Small Grants Scheme (SGS) with the grant number C09/(S177)/1321/2016 (1).

\section{References}

[1] Kuang Y., Islam N., Nabae Y. et al.: Angew. Chem. Int. Edit., 2010, 49, 436. https://doi.org/10.1002/anie.200904362

[2] Arena F., Gumina B., Lombardo A. et al.: Appl. Catal. B, 2015, 162, 260. https://doi.org/10.1016/j.apcatb.2014.06.054

[3] Lingaiah N., Reddy K., Babu N. et al.: Catal. Commun., 2006, 7, 245. https://doi.org/10.1016/j.catcom.2005.10.013

[4] Weng Z., Wang J., Jian X.: Catal. Commun., 2008, 9, 1688. https://doi.org/10.1016/j.catcom.2007.11.017

[5] Davis S., Ide M., Davis R.: Green Chem., 2013, 15, 17. https://doi.org/10.1039/C2GC36441G

[6] Gu Y., Li C., Bai J., Liang H.: J. Photochem. Photobiol. A., 2018, 351, 87. https://doi.org/10.1016/j.jphotochem.2017.10.013 [7] Sun J., Tong X., Liu Z. et al.: Catal. Commun., 2016, 85, 70. https://doi.org/10.1016/j.catcom.2016.07.018

[8] Dayan O.,Tercan M., Özdemir N.: J. Mol. Struct., 2016, 1123, 35. https://doi.org/10.1016/j.molstruc.2016.06.017

[9] Hu Z., Zhao Y., Liu J. et al.: J. Colloid Interf. Sci., 2016, 483, 26. https://doi.org/10.1016/j.jcis.2016.08.010

[10] Xu J., Shang J-K., Chen Y. et al.: Appl. Catal. A., 2017, 542, 380. https://doi.org/10.1016/j.apcata.2017.05.036

[11] Jung D., Lee S., Na K.: Solid State Sci., 2017, 72, 150. https://doi.org/10.1016/j.solidstatesciences.2017.08.022

[12] Choudhary V., Chaudhari P., Narkhede V.: Catal. Commun., 2003, 4, 171. https://doi.org/10.1016/S1566-7367(03)00027-X

[13] Feng X., Lv P., Sun W. et al.: Catal. Commun., 2017, 99, 105. https://doi.org/10.1016/j.catcom.2017.05.013

[14] Elmaci G., Ozer D.,Zumreoglu-Karan B.: Catal. Commun., 2017, 89, 56. https://doi.org/10.1016/j.catcom.2016.10.027

[15] Su Y., Wang L., Liu Y. et al.: Catal. Commun., 2007, 8, 2181. https://doi.org/10.1016/j.catcom.2007.04.020

[16] Bansal V., Thankachana P., Prasad R.: Appl. Catal. A, 2010, 381, 8. https://doi.org/10.1016/j.apcata.2010.03.027

[17] Chen S., Liu G., Yadegari H. et al.: J. Mater. Chem. A., 2015, 3, 2559. https://doi.org/10.1039/C5TA00004A

[18] Murashima Y., Ohtani R., Matsui T. et al.: Dalton Trans., 2015, 44, 5049. https://doi.org/10.1039/C5DT00299K

[19] Hu J., Sun K., He D., Xu B.: Chin. J. Catal., 2007, 28, 1025. https://doi.org/10.1016/S1872-2067(08)60001-7

[20] Tang Q., Huang X., Chen Y. et al.: J. Mol. Catal. A, 2009, 301, 24. https://doi.org/10.1016/j.molcata.2008.11.003

[21] Shao Y., Sui J., Yin G., Gao Y.: Appl. Catal. B, 2008, 79, 89. https://doi.org/10.1016/j.apcatb.2007.09.047

[22] Yu X., Huo Y., Yang J. et al.: Appl. Surf. Sci., 2013, 280, 450. https://doi.org/10.1016/j.apsusc.2013.05.008

[23] Navalon S., Dhakshinamoorthy A., Alvaro M., Garcia H.: Chem. Rev., 2014, 114, 6179. https://doi.org/10.1021/cr4007347

[24] Zhu J., Faria J., Figueiredo J., Thomas A.: Chem. Eur. J., 2011, 17, 7112. https://doi.org/10.1002/chem.201003025

[25] Nguyen Q., Quan N.: Reac. Kinet. Mech. Cat., 2015, 114, 147. https://doi.org/10.1007/s11144-014-0773-4

[26] Kimi M., Jaidie M., Pang S.: J. Phys. Chem. Solid., 2018, 112, 50. https://doi.org/10.1016/j.jpcs.2017.09.008 
[27] Wu G., Gao Y., Ma F. et al.: Chem. Eng. J., 2015, 271, 14. https://doi.org/10.1016/j.cej.2015.01.119

[28] Vinayagam M., Ramachandran S., Ramya V., Sivasamy A.: J. Environ. Chem. Eng., 2018, 6, 3726.

https://doi.org/10.1016/j.jece.2017.06.005

[29] Olmos C., Chinchilla L., Delgado J. et al.: Catal. Lett., 2016, 146, 144. https://doi.org/10.1007/s10562-015-1641-1

[30] Ali R., Adil S., Al-warthan A., Siddiqui M.: J. Chem., 2013, 2013. https://doi.org/10.1155/2013/367261

[31] Zhou C., Guo Z., Dai Y. et al.: Appl. Catal. B., 2016, 181, 118. https://doi.org/10.1016/j.apcatb.2015.07.048

[32] Alonso D., Wettstein S., Dumesie J.: Chem. Soc. Rev., 2012, 41, 8075. https://doi.org/10.1039/c2cs35188a

[33] Dandekar A., Baker R., Vannice M.: J. Catal., 1999, 183, 131. https://doi.org/10.1006/jcat.1999.2390

[34] Macia-Agullo J., Cazorla-Amoros D., Linares-Solano A. et al.: Catal. Today, 2005, 102, 248.

https://doi.org/10.1016/j.cattod.2005.02.023

[35] Li W., Wang A., Liu X., Zhang T.: Appl. Catal. A, 2012, 433-

434, 146. https://doi.org/10.1016/j.apcata.2012.05.014

[36] Wu G., Gao Y., Ma F. et al.: Chem. Eng. J., 2015, 271, 14.

https://doi.org/10.1016/j.cej.2015.01.119
[37] Santra C., Pramanik M., Bando K. et al.: J. Mol. Catal. A, 2016, 418-419, 41. https://doi.org/10.1016/j.molcata.2016.03.026

Received: May 23, 2018 / Revised: June 06, 2018 / Accepted: September 18, 2018

\section{ХАРАКТЕРИСТИКА МАРГАНЕЦЬ-МІДНОГО КАТАЛІЗАТОРА НА АКТИВОВАНОМУ ВУГЛЕЦІ, СИНТЕЗОВАНОМУ МЕТОДОМ ВИСАДЖЕННЯ}

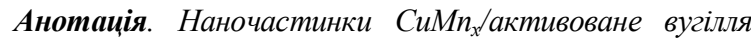
$(A B, x=0,1 ; 0,2 ; 0,5 i$ 1) отримували методом висадження. Вивчено каталітичну характеристику $\mathrm{CuMn}_{x} / A B$ для окиснення бензилового спирту до бензальдегіду. Показано, щяо молярне співвідношення Мn відіграє важливу роль у каталітичній характеристиці. Оптимальна кількість Мп становить 0,1 при максимальному перетворенні бензилового спирmy $63 \%$

Ключові слова: окиснення бензилового спирту, бiметалічний каталізатор, активований вуглець, мідь, марганецьв. 